\title{
Continuous, Large-Volume Hydrodissection to Protect Delicate Structures around the Thyroid throughout the Radiofrequency Ablation Procedure
}

\author{
Yanping $\mathrm{Ma}^{\mathrm{a}}$ Tao $\mathrm{Wu}^{\mathrm{a}}$ Zhicheng Yao ${ }^{\mathrm{b}}$ Bowen Zheng ${ }^{\mathrm{a}}$ Lei Tan ${ }^{\mathrm{a}}$ Ge Tong ${ }^{\mathrm{a}}$ \\ Yufan Lian ${ }^{a}$ Jung Hwan Baek ${ }^{c}$ Jie Ren ${ }^{a}$ \\ aDepartment of Medical Ultrasound, The Third Affiliated Hospital of Sun Yat-sen University, Guangzhou City, China; \\ ${ }^{\mathrm{b}}$ General Surgery Department, The Third Affiliated Hospital of Sun Yat-sen University, Guangzhou City, China; \\ 'Department of Radiology and Research Institute of Radiology, University of Ulsan College of Medicine, Seoul, \\ South Korea
}

\section{Keywords}

Hydrodissection · Benign thyroid nodules · Radiofrequency ablation · Ultrasound-guided ablation · Interventional ultrasonography

\begin{abstract}
Introduction: Small-volume hydrodissection liquid dissipates rapidly and confers only short-term protection during radiofrequency ablation (RFA) of benign thyroid nodules. The aim of this study was to establish a safe method for continuous, large-volume hydrodissection. Methods: A long needle was inserted and positioned outside the thyroid capsule; $5 \%$ glucose was injected to maintain a 3- to $5-\mathrm{mm}$ continuous safety buffer. From October 2015 to July 2020, 166 patients underwent hydrodissection with different volumes, and ablation efficacy and complications associated with different liquid volumes ( $\leq 40 \mathrm{~mL}$ vs. $>40 \mathrm{~mL}$ ) were compared at 1-month postprocedure. Moreover, $20 \mathrm{~mL}$ liquid (equivalent to $250 \mathrm{~mL}$ in the human body) was injected around the thyroid of a rhesus monkey, after which CT scans were used to visualize the liquid's fate and verify its safety. Results: The 51
\end{abstract}

karger@karger.com www.karger.com/etj

Karger"

BOPEN ACCESS
(C) 2021 The Author(s)

Published by S. Karger AG, Basel

This is an Open Access article licensed under the Creative Commons Attribution-NonCommercial-4.0 International License (CC BY-NC) (http://www.karger.com/Services/OpenAccessLicense), applicable to the online version of the article only. Usage and distribution for commercial purposes requires written permission. patients with $10-40 \mathrm{~mL}$ injections and 116 patients with larger injections $(45-450 \mathrm{~mL}$ ) showed similar complete ablation rates $(88.46 \%$ vs. $90.44 \%, p=0.582)$, comparable 6 -month VRR ( $82.79 \%$ vs. $76.62 \%, p=0.079)$, and complication incidences, although the latter group had larger nodules $(9.11 \mathrm{~mL}$ vs. $13.79 \mathrm{~mL}, p=0.003)$, more energy delivered (3.44 kcal vs. $6.04 \mathrm{kcal}, p<0.001$ ), and longer operation times (51.37 min vs. $69.2 \mathrm{~min}, p<0.001$ ). In the animal experiment, the $20 \mathrm{~mL}$ of liquid diffused quickly (within $10 \mathrm{~min}$ ) from the vicinity of the thyroid to the mediastinum and retropharyngeal space. It was observed in the kidneys at $10 \mathrm{~min}$ and disappeared from the neck and chest space by $24 \mathrm{~h}$. Conclusions: Continuous, large-volume hydrodissection can protect the delicate structures around the thyroid throughout the RFA procedure and might be beneficial in large thyroid nodule ablation.

(c) 2021 The Author(s).

Published by S. Karger AG, Basel

Yanping Ma, Tao $\mathrm{Wu}$, and Zhicheng Yao contributed equally to this work. Jung Hwan Baek and Jie Ren are corresponding authors and contributed equally to this work.
Correspondence to:

Jung Hwan Baek, radbaek@naver.com

Jie Ren, renjie@mail.sysu.edu.cn 


\section{Introduction}

Thyroid nodules constitute a frequently encountered clinical problem [1,2], and some benign thyroid nodules (BTNs) may require treatment for associated symptoms and/or because of cosmetic problems. As curative surgery has several drawbacks $[3,4]$, radiofrequency ablation (RFA), a minimally invasive treatment modality, was introduced and has been reported to be safe and effective for treating BTNs [5-8]. However, the delicate structures around the thyroid are likely to be damaged during thermal ablation [9]. How to protect vital structures from heat injuries plays a significant role in RFA for BTNs.

The hydrodissection technique is a protective measure used to reduce heat injury to adjacent structures [10] and has been cited in some guidelines [11-13]. Hydrodissection involves injecting liquids around the thyroid capsule, ensuring a safe distance between the thyroid and critical structures [10-13].

However, little attention has been given to the amount of hydrodissection liquid. In a few studies, $10-40 \mathrm{~mL}$ was considered effective $[12,14,15]$. Nonetheless, the duration of 10-20 mL saline was only 5-15 min [16], which limits its use to short procedures. For time-consuming procedures, which can even take up to $1 \mathrm{~h}$ in microwave ablation [17], this duration may be too short to cover the whole ablation process. One possible solution would be to increase the volume of injected liquid. Lee $\mathrm{M}$ et al. [18] injected as much as $260 \mathrm{~mL}$ cold $5 \%$ glucose into the tracheoesophageal groove of a 47 -year-old male to reduce nerve damage during RFA. Similarly, Cui et al. [19] used $200 \mathrm{~mL}$ saline during microwave ablation of a $5.4-\mathrm{cm}$ substernal goiter. This innovative and seminal work pioneered a new approach: large-volume hydrodissection. However, no study has adequately explored whether some side effects including airway compression increase with injections exceeding $40 \mathrm{~mL}$ of liquid, and the location and distribution of the dwindling liquid remain poorly understood.

Based on the clinical experiences of $>200$ patients who underwent RFA of BTNs, we established a method of intermittent and repeated injections of hydrodissection liquid that could inject $>40 \mathrm{~mL}$ of liquid. The complications and ablation efficacy in 166 patients who underwent this method were retrospectively analyzed. In addition, the fate of the hydrodissection liquid was verified by injecting $5 \%$ glucose around the thyroid of an adult rhesus monkey. This investigation enhances our understanding of the hydrodissection technique and might help improve the safety of time-consuming ablations.

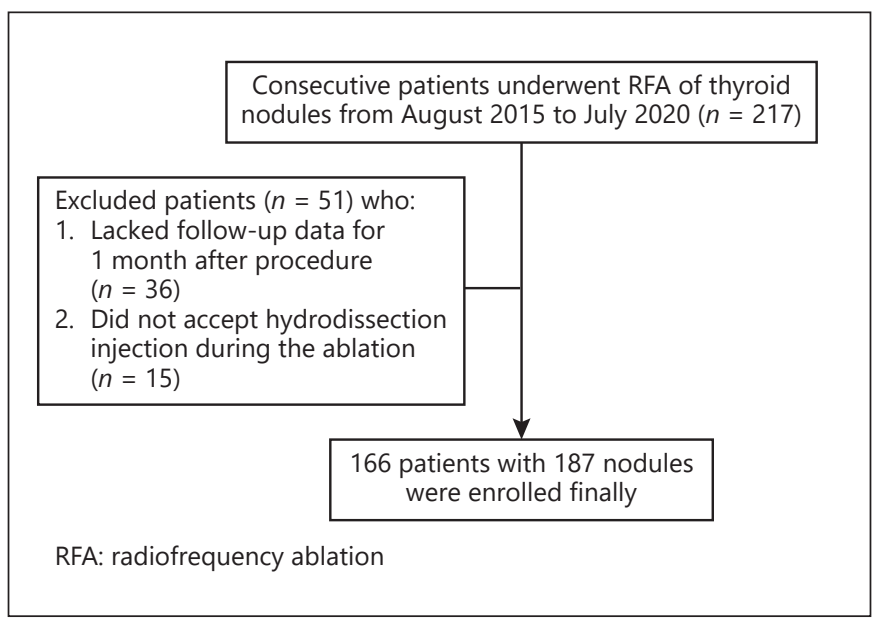

Fig. 1. Flowchart of patient enrollment. RFA, radiofrequency ablation.

\section{Materials and Methods}

\section{Patients}

This study was approved by the Review Board of the Third Affiliated Hospital of Sun Yat-sen University and was registered at www.chictr.org.cn (ChiCTR-INR-16007884). From October 2015 to July 2020, 217 consecutive patients were treated with RFA of BTNs in our hospital. All patients signed an informed consent form before receiving treatment.

All enrolled patients fulfilled the criteria established by the Korean Society of Thyroid Radiology for BTNs [11, 12, 20] and underwent hydrodissection. The exclusion criteria were the inability to tolerate treatment and lack of postoperative 1-month follow-up information (online suppl. Table 1; see online Supplementary Materials).

After excluding 51 patients according to the above criteria, 166 patients were enrolled (Fig. 1). To explore whether there were differences in ablation efficacy and complications in patients who received different hydrodissection volumes, we divided the patients into 2 groups according to the conventional volume $(40 \mathrm{~mL})$ in the previous study: group 1 (hydrodissection volume $\leq 40 \mathrm{~mL}$ ) and group 2 (hydrodissection volume $>40 \mathrm{~mL}$ ).

\section{Pretreatment Evaluation}

Before the procedure, the ultrasonography (US) findings, fineneedle aspiration findings, contrast-enhanced US (CEUS) findings, and laboratory and clinical results were evaluated. The US examination included characterization of the location, shape, size, margins, solid/cystic proportions, echogenicity, calcification status, and internal vascularity of each nodule. The nodule volume was calculated as follows: volume $=\pi \mathrm{abc} / 6(\mathrm{a}, \mathrm{b}$, and $\mathrm{c}: 3$ diameters of the nodule). Laboratory tests included serum thyroid function tests and antibody tests.

\section{Hydrodissection Technique and RFA Procedure}

Patients were placed in the supine position with their necks extended. Local anesthesia with $2 \%$ lidocaine was applied from the skin puncture point to the outer capsule of the thyroid. A long 
needle (22 gauge, 70-mm length; Hakko Co., Ltd.) was inserted and maintained outside the thyroid capsule, and $5 \%$ glucose was injected by using a catheter until successful hydrodissection was established. Successful hydrodissection was a 3- to 5-mm barrier between the outer thyroid capsule and common carotid artery, the posterior thyroid capsule and trachea/esophagus, the thyroid and parathyroid, and the thyroid posterior capsule and recurrent laryngeal nerves $[7,8,12]$. If no breathing difficulty was reported during injection, we began ablation. During ablation, we ensured that the tip of the long needle was located between the posterior thyroid capsule and longus colli muscle (online suppl. Figure). If the distance was $<3 \mathrm{~mm}$, a repeat injection was performed to guarantee a safety buffer of at least $3 \mathrm{~mm}$.

We used an RF generator (VIVA RF System ${ }^{\circledR}$; STARmed) and an internally cooled 18-gauge, 70-mm length, 7- or 10-mm, activetip electrode (Star RF Electrode ${ }^{\circledR}$; STARmed). The moving-shot technique was used to perform multiple ablations until the nodule was completely covered by the transient hyperechoic area [21,22]. CEUS was used to evaluate whether the appearance of an entire nodule changed to nonenhancement. For enhanced nodules, an additional ablation was performed.

Any specific complaints or concerns were monitored immediately after the procedure and during the follow-up period. Safety was defined as the incidence of complications and side effects. Major and minor complications and side effects were defined according to the criteria established by the Society of Interventional Radiology $[9,23-26]$.

Follow-Up

Postprocedural follow-up was performed 1, 3, and 6 months after treatment. At the visit, a US examination, CEUS examination, and serum thyroid tests were performed. Complete ablation was defined as the entire nodule being nonenhanced on CEUS. The volume reduction ratio (VRR) and complete ablation rate (CAR) are important indicators reflecting ablation efficacy [27]:

$\operatorname{VRR}(\%)=[$ initial volume $(\mathrm{mL})-$ final volume $(\mathrm{mL})] /$ initial volume $(\mathrm{mL}) \times 100 \%(8)$,

$\mathrm{CAR}=$ number of nodules that achieved complete ablation $(N) /$ total number of nodule $(N) \times 100 \%$.

\section{Animal Data}

The adult male rhesus monkey was 22 years old, with a body weight of $10 \mathrm{~kg}$. After general anesthesia was administered, the monkey was laid in a supine position with the neck hyperextended. Under US guidance, a 22-gauge needle was inserted outside the thyroid capsule. Then, a $20 \mathrm{~mL}$ mixture containing $10 \mathrm{~mL}$ 5\% glucose and $10 \mathrm{~mL}$ iohexol was injected for hydrodissection. Twenty milliliters in the monkey is equivalent to $250 \mathrm{~mL}$ in a $60-\mathrm{kg}$ human body [28]. Successful hydrodissection was defined as detailed above. A thin-layer CT scan of the neck, chest, and abdomen was performed $10 \mathrm{~min}, 1$ $\mathrm{h}, 2 \mathrm{~h}$, and $24 \mathrm{~h}$ after the liquid injection. Enhancement of the perithyroidal space, mediastinum, blood vessels, and urinary system was observed to confirm where the injected liquid went. After the monkey woke up, its vital signs were monitored for $72 \mathrm{~h}$.

\section{Statistical Analysis}

Continuous parameters are expressed as mean \pm standard deviation, while categorical variables are expressed as numbers and percentages. Independent $t$ tests and Mann-Whitney $\mathrm{U}$ tests for continuous variables and Fisher's exact tests $/ \chi^{2}$ tests for categorical variables were employed to perform statistical analysis of betweengroup comparisons. In addition, statistical significance was set at $p<0.05$. SPSS version 23.0 (IBM, Armonk, NY, USA) was used for all statistical analyses.

\section{Results}

A total of 166 patients with 187 nodules completed their treatment with an average hydrodissection liquid volume of $113.68 \mathrm{~mL}$ (10-450 mL). Among them, only 1 patient experienced hoarseness, 2 patients had hematomas, and 3 patients vomited (Fig. 2; online suppl. Table 2).

Patient age, sex, location of nodules, and serum thyroid tests were comparable between group 1 (hydrodissection volume $\leq 40 \mathrm{~mL}$ ) and group 2 (hydrodissection volume $>40 \mathrm{~mL}$ ) (Table 1 ). The maximum nodule diameter and baseline volume, solid portion, operation time, and total energy delivered in group 2 were significantly greater than those in group 1. Furthermore, group 2 had more nodules with a maximum diameter of $>40 \mathrm{~mm}$ than group 1 (68/135 vs. 14/52).

Regarding ablation efficacy, the CAR at the 1-month follow-up and VRR at the 6-month follow-up showed no significant difference between the 2 groups $(90.44 \%$ vs. $88.46 \%, p=0.582 ; 76.62 \% \pm 17.74 \%$ vs. $82.79 \% \pm 13.78 \%$, $p=0.079$; respectively), although the VRR at the $1-$ and 3-month follow-ups of group 2 was lower than that of group 1 (39.94\% $\pm 28.62 \%$ vs. $50.25 \% \pm 23.78 \%, p=0.035$; $64.67 \% \pm 20.50 \%$ vs. $73.56 \% \pm 17.63 \%, p=0.020$; respectively). There were no significant differences in 1-month serum tests between the 2 groups.

Regarding complications and side effects, the 2 groups did not differ significantly in major complications, minor complications, or side effects (Table 2). The number of patients who suffered pain, chest tightness, edema, and feelings of choking when eating in group 2 was clearly greater than that in group 1 .

After injecting a $20 \mathrm{~mL}$ mixture around the thyroid of the rhesus monkey, serial CT and reconstruction images of the neck and chest showed the location and movement of the hydrodissection liquid. The liquid was injected into the visceral space first and then quickly spread around the thyroid and formed a working barrier, occupying the potential space around the neck, up to the chin, down to the mediastinum, and posterior to the retropharyngeal space in $10 \mathrm{~min}$. In the next $2 \mathrm{~h}$, the liquid spread more widely. The dynamic changes indicated that a potentially large space around the neck and mediastinum was able to store a large volume of liquid. 

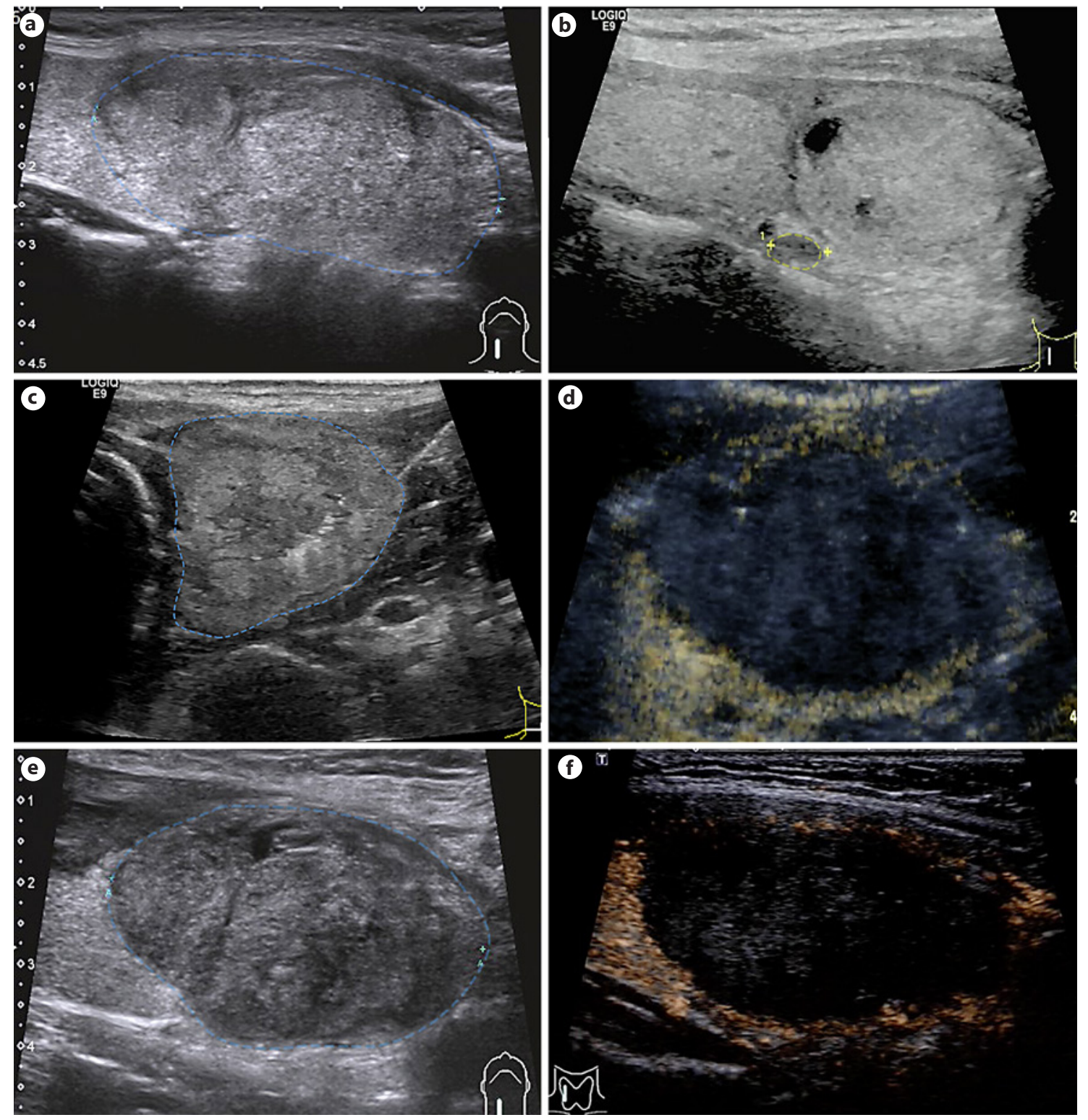

Fig. 2. A case of intermittent, repeated injection of $350 \mathrm{~mL}$ hydrodissection liquid. A 30-year-old female patient had a nodule in the right lobe of the thyroid. Preoperative fine-needle aspiration cytologic examination confirmed its benignancy. The blue line in the figure shows the rim of the nodule boundary. Preoperative images show that the rim of the $52 \times 36 \times 32 \mathrm{~mm}$ nodule was clear and smooth (a). Preoperative assessment of dangerous structures around the nodules. The nodule was adjacent to the cervical sympathetic nerve node, recurrent laryngeal nerve, trachea, and esophagus, and the yellow line shows the posterior cervical sympathetic ganglion (b). Glucose (5\%) was injected to separate the nodule and the surrounding structures at a distance of $>3 \mathrm{~mm}$ (c). After assurance of a sufficient safety buffer, multiple ablations were performed until the nodule was completely covered by a transient hyperechoic area in three-dimensional space. Then, CEUS was performed again to confirm that the nodule had been completely ablated (d). One-day US images showed that the hydrodissection liquid was absorbed completely (e). One-month US images showed that the nodule achieved complete ablation and was reduced to 44 $\times 32 \times 10 \mathrm{~mm}(\mathrm{VRR}=56.5 \%)(\mathbf{f})$. CEUS, contrast-enhanced ultrasonography; US, ultrasonography; VRR, volume reduction ratio. 
Table 1. Patient characteristics and treatment parameters of 2 groups

\begin{tabular}{|c|c|c|c|}
\hline Variables & $\begin{array}{l}\text { Group } 1 \\
\text { (hydrodissection } \\
\text { volume } \leq 40 \mathrm{~mL} \text { ) }\end{array}$ & $\begin{array}{l}\text { Group } 2 \\
\text { (hydrodissection } \\
\text { volume }>40 \mathrm{~mL} \text { ) }\end{array}$ & $p$ value \\
\hline \multicolumn{4}{|l|}{ Patient characteristics } \\
\hline Patients, $n$ & 51 & 115 & \\
\hline Age, years & $40.67 \pm 15.53$ & $42.89 \pm 13.29$ & 0.348 \\
\hline Female/male & $37 / 14$ & $96 / 29$ & 0.104 \\
\hline \multicolumn{4}{|l|}{ Nodule characteristics } \\
\hline Nodules, $n$ & 52 & 135 & \\
\hline \multicolumn{4}{|l|}{ Location of nodules } \\
\hline Left & 21 & 59 & 0.641 \\
\hline Right & 28 & 72 & \\
\hline Isthmus & 3 & 4 & \\
\hline Maximum diameter, mm & $32.54 \pm 8.41$ & $38.38 \pm 10.61$ & $<0.001$ \\
\hline $20-29$ & 21 & 33 & \\
\hline $30-39$ & 17 & 34 & \\
\hline$>40$ & 14 & 68 & \\
\hline Baseline volume, $\mathrm{mL}$ & $9.11 \pm 8.55$ & $13.79 \pm 11.53$ & 0.003 \\
\hline Solid, \% & $52.40 \pm 38.07$ & $68.2 \pm 35.03$ & 0.020 \\
\hline \multicolumn{4}{|l|}{ Baseline thyroid tests } \\
\hline TSH, ulU/mL & $1.63 \pm 0.99$ & $1.22 \pm 0.80$ & 0.008 \\
\hline $\mathrm{FT3}, \mathrm{pmol} / \mathrm{L}$ & $4.91 \pm 3.63$ & $4.46 \pm 0.77$ & 0.615 \\
\hline $\mathrm{FT} 4, \mathrm{pmol} / \mathrm{L}$ & $13.83 \pm 2.63$ & $13.50 \pm 3.13$ & 0.373 \\
\hline TPOAb, IU/mL & $0.41(0.15-2.80)$ & $0.62(0.27-9.32)$ & 0.098 \\
\hline $\operatorname{TgAb}, \mathrm{IU} / \mathrm{mL}$ & $1.67(1.04-3.05)$ & $1.76(1.07-11.21)$ & 0.422 \\
\hline \multicolumn{4}{|l|}{ Treatment parameters } \\
\hline Hydrodissection volume, $\mathrm{mL}$ & $26.19 \pm 9.62$ & $152.36 \pm 102.90$ & $<0.001$ \\
\hline Operation time, $\min$ & $51.37 \pm 20.15$ & $69.23 \pm 27.46$ & $<0.001$ \\
\hline Total energy delivered, kcal & $3.44 \pm 2.54$ & $6.04 \pm 4.03$ & $<0.001$ \\
\hline \multicolumn{4}{|l|}{ 1-month follow-up } \\
\hline CAR, \% & $88.46(46 / 52)$ & $90.44(123 / 135)$ & 0.582 \\
\hline Volume of nodules, $\mathrm{mL}$ & $4.25 \pm 4.18(10-40)$ & $7.52 \pm 6.98(45-450)$ & $<0.001$ \\
\hline VRR, \% & $50.25 \pm 23.78$ & $39.94 \pm 28.62$ & 0.035 \\
\hline \multicolumn{4}{|l|}{ 1-month thyroid tests } \\
\hline TSH, ulU/mL & $1.90 \pm 3.90$ & $1.27 \pm 0.92$ & 0.515 \\
\hline $\mathrm{FT3}, \mathrm{pmol} / \mathrm{L}$ & $4.52 \pm 0.91$ & $4.53 \pm 149$ & 0.698 \\
\hline $\mathrm{FT} 4, \mathrm{pmol} / \mathrm{L}$ & $14.01 \pm 2.77$ & $13.34 \pm 2.84$ & 0.052 \\
\hline TPOAb, IU/mL & $0.71(0.27-2.28)$ & $0.61(0.28-8.34)$ & 0.518 \\
\hline $\operatorname{TgAb}, \mathrm{IU} / \mathrm{mL}$ & $1.50(1.00-2.08)$ & $2.54(1.13-12.53)$ & 0.112 \\
\hline \multicolumn{4}{|l|}{ 3-month follow-up } \\
\hline Volume of nodules, mL & $2.13 \pm 1.96$ & $4.83 \pm 5.27$ & $<0.001$ \\
\hline VRR, $\%$ & $73.56 \pm 17.63$ & $64.67 \pm 20.50$ & 0.020 \\
\hline \multicolumn{4}{|l|}{ 6-month follow-up } \\
\hline Volume of nodules, $\mathrm{mL}$ & $2.00 \pm 3.44$ & $3.09 \pm 4.05$ & 0.032 \\
\hline VRR, \% & $82.79 \pm 13.78$ & $76.62 \pm 17.74$ & 0.079 \\
\hline
\end{tabular}


Table 2. Complications and side effects of 2 groups

\begin{tabular}{|c|c|c|c|}
\hline Complication or side effect & $\begin{array}{l}\text { Group } 1 \\
\text { (hydrodissection } \\
\text { volume } \leq 40 \mathrm{~mL} \text { ) }\end{array}$ & $\begin{array}{l}\text { Group } 2 \\
\text { (hydrodissection } \\
\text { volume }>40 \mathrm{~mL} \text { ) }\end{array}$ & $p$ value \\
\hline \multicolumn{4}{|l|}{ Major, $n(\%)$} \\
\hline Voice change (>1 month) & $1(1.96)$ & 0 & 0.307 \\
\hline \multicolumn{4}{|l|}{ Minor, $n(\%)$} \\
\hline Hematoma & 0 & $2(1.74)$ & 1.000 \\
\hline Nausea and vomiting & $2(3.92)$ & $1(0.87)$ & 0.465 \\
\hline \multicolumn{4}{|l|}{ Side effect, $n(\%)$} \\
\hline Pain (VAS $\geq 7$ ) & $3(5.88)$ & $8(6.96)$ & 1.000 \\
\hline Vasovagal reaction & $3(5.88)$ & $2(1.74)$ & 0.343 \\
\hline BP change & $3(5.88)$ & $3(2.61)$ & 0.554 \\
\hline Swelling of neck & $1(1.96)$ & $2(1.74)$ & 1.000 \\
\hline Chest tightness & 0 & $2(1.74)$ & 1.000 \\
\hline Edema & $2(3.92)$ & $5(4.35)$ & 1.000 \\
\hline Coughing & $1(1.96)$ & $2(1.74)$ & 1.000 \\
\hline Paraesthesia pharynges & $5(9.80)$ & $8(6.96)$ & 0.529 \\
\hline Feeling of choking when eating & $1(1.96)$ & 7 (6.09) & 0.452 \\
\hline Dizziness & $1(1.96)$ & $3(2.61)$ & 1.000 \\
\hline Burning sensation & $3(5.88)$ & $1(0.87)$ & 0.163 \\
\hline
\end{tabular}

Notably, the amount of liquid in the neck and chest images decreased from $10 \mathrm{~min}$ to $2 \mathrm{~h}$, and the $24-\mathrm{h}$ images showed no liquid, which indicated rapid absorption of the liquid. Moreover, there was enhancement in the kidneys, ureters, and bladder in the 10-min, 1-h, 2-h and 24 -h images. The images revealed that the abundant capillaries and lymphatic vessels around the neck and mediastinum could quickly absorb the retained liquid, and the excretion route of the hydrodissection liquid was through the urinary system (Fig. 3, 4).

Regarding clinical manifestations, the monkey was continuously monitored and exhibited stable vital signs. It woke up $1 \mathrm{~h}$ after the last CT examination and survived for $>1$ month subsequently. Notably, the trachea moved to the right side slightly, without lumen diameter changes or manifestations of dyspnea. The full lumen of the trachea allowed sufficient air to be inhaled, thus avoiding serious breathing difficulties due to the injection of hydrodissection liquid.

\section{Discussion}

The hydrodissection technique is a protective measure to reduce heat injury to adjacent structures in RFA of BTNs. To maintain continuous hydrodissection protection throughout some time-consuming ablation processes, we established a method of intermittent, repeated injections of hydrodissection liquid. This method was proven to be safe and effective from bench to bed.
Since we established the method, 166 patients have been injected with an average of $113.68 \mathrm{~mL}$ of $5 \%$ glucose. The successful use of this large-volume hydrodissection liquid volume indicates the feasibility and safety of this proposed technique. Compared with previous studies, our method was able to apply a larger volume of liquid around the thyroid capsule $[12,14,15]$. In addition, a large volume of liquid $(45 \sim 450 \mathrm{~mL})$ did not increase the occurrence of complications compared with previous studies (0-10\%) [25]. Regarding liquid volume, patients receiving $>40 \mathrm{~mL}$ of hydrodissection liquid had larger BTNs, more energy delivered, and longer operation times than those receiving $<40 \mathrm{~mL}$. However, CAR, 6-month VRR, and incidence of complications were comparable between the 2 groups. These results indicated that a large volume of liquid was required to protect the surrounding structures because large BTNs need longer operation times and more energy delivered. Furthermore, with good protection from large-volume hydrodissection, large BTNs could be completely ablated during the first ablation, and a comparable volume reduction was achieved without increasing the incidence of complications. Our user-friendly method showed its superiority in RFA of large BTNs.

Another finding worth noting was the number of patients with side effects such as pain and chest tightness, which might be related to the compression caused by the larger volume of liquid. Indeed, more patients suffered side effects among those who received more hydrodissec- 


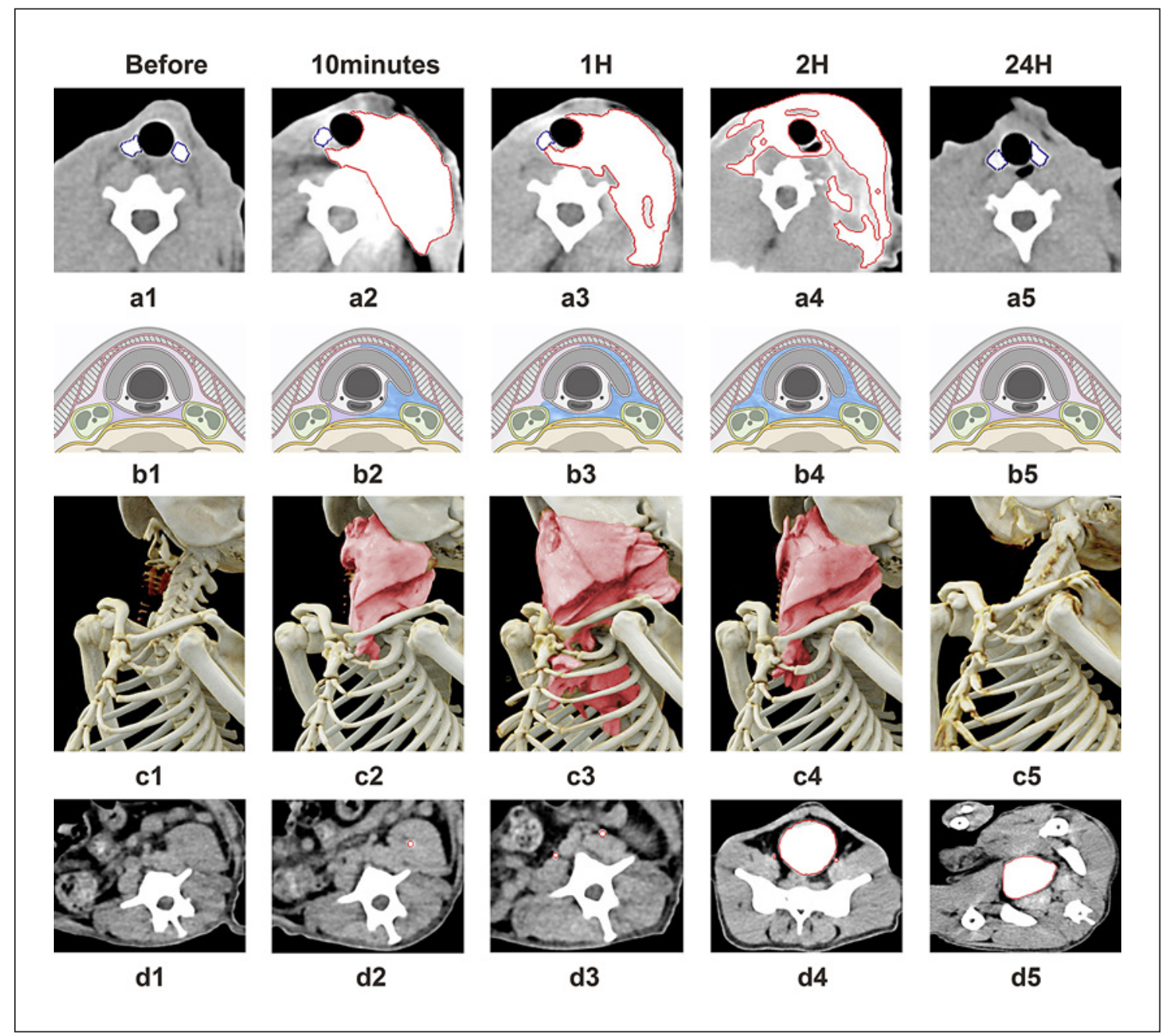

Fig. 3. CT and reconstruction images of the 22-year-old rhesus monkey (weight $=10 \mathrm{~kg}$ ) after injecting $20 \mathrm{~mL}$ hydrodissection liquid $(10 \mathrm{~mL} 5 \%$ glucose and $10 \mathrm{~mL}$ iohexol) around the left thyroid lobe. a: CT images of the neck. a1-a5 show that $10 \mathrm{~min}$ to $2 \mathrm{~h}$ after injection, liquid spread around the visceral space and extended to the retropharyngeal space and the opposite side. Twenty-four hours after liquid injection, no liquid remained in the neck. b: schematic diagrams of the neck corresponding to a1-a5. c: recon-

tion liquid injections. In addition, although the nodule VRR of patients receiving more hydrodissection liquid was lower at the 1-and 3-month follow-up, the 6-month VRR was not significantly different between the 2 groups. This result could be explained by the fact that large BTNs need more time to absorb necrotic tissue; thus, the volume reduction in large BTNs was not as good as that in small BTNs. This is consistent with previous literature reports $[7,15,29,30]$.

Large-Volume Hydrodissection in RFA of Thyroid Nodules struction images of the chest. $\mathrm{cl}-\mathrm{c} 5$ show that $10 \mathrm{~min}$ to $2 \mathrm{~h}$ after injection, liquid spread around the visceral space and extended to the mediastinum. Twenty-four hours after liquid injection, no liquid remained in the chest. $\mathrm{d}$ : CT images of the abdomen. d1-d5 show that $10 \mathrm{~min}$ to $2 \mathrm{~h}$ after injection, the kidneys, ureters, and bladder were enhanced by hydrodissection liquid absorption. Twenty-four hours after liquid injection, the bladder was still enhanced as a result of residue iohexol.

Finally, we injected a $20 \mathrm{~mL}$ mixture around the thyroid of a rhesus monkey, which has neck structures similar to those of humans, to show the fate of the hydrodissection liquid. There were several striking findings in this experiment. First, the $20 \mathrm{~mL}$ mixture diffused quickly from the vicinity of the thyroid to the mediastinum and retropharyngeal space and was then cleared by the hemolymphatic system and excreted by the urinary system. This hydrodissection liquid diffusion process was similar to the spreading process of abscesses and effusions of the

Eur Thyroid J 2021;10:495-503 


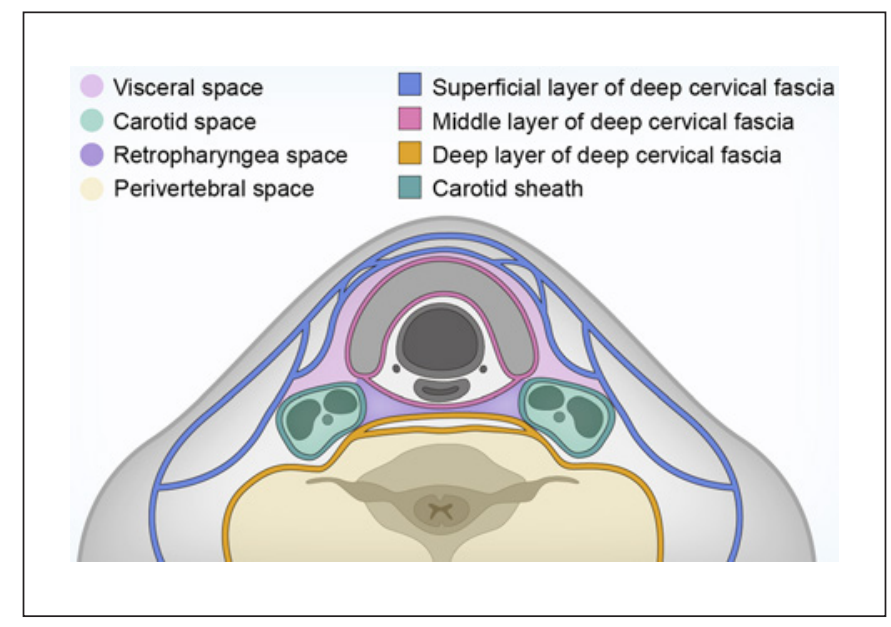

Fig. 4. Schematic diagram of deep neck space.

head and neck, extending through the visceral space and even reaching the mediastinum $[31,32]$. Second, such a large amount of liquid led only to rightward deviation of the trachea, without causing marked narrowing in the diameter or airway compression. Ultimately, the monkey woke up $1 \mathrm{~h}$ after the last CT examination and survived for $>1$ month.

The animal experiment revealed that the hydrodissection liquid did not behave like post-thyroidectomy hemorrhage, which causes serious complications, including airway compression, when the volume is approximately $50 \mathrm{~mL}[33,34]$. This occurs because postoperative hemorrhage quickly coagulates into blood clots and thus compresses the trachea. However, the injected liquid lacked blood cells and coagulation factors. The lack of coagulation components provided the hydrodissection liquid with good flowability and thus allowed it to spread freely. Not only did the liquid not agglutinate, but it also spread to the space around the thyroid. Then, the full diameter of the trachea ensured sufficient air inhalation and did not affect the vital signs or survival of the monkey. This is the first study to report the fate of hydrodissection liquid injected around the thyroid in animal experiments. The animal study theoretically demonstrated the safety of a large volume of hydrodissection liquid.

Several limitations should be acknowledged. First, the safety threshold of the hydrodissection volume has not been shown. Although no complications occurred in the 2 patients who were injected with as much as $450 \mathrm{~mL}$ of liquid, it is still impossible to answer whether $450 \mathrm{~mL}$ or more liquid is the upper limit for hydrodissection vol- umes. Fortunately, by monitoring the amount of fluid around the thyroid and supplementing it in a timely manner, the 3- to 5-mm safety buffer was shown to be effective and safe. Second, given that this is a retrospective cohort study, there are inherent problems related to the study design. Third, there were some differences between the rhesus monkey and humans when the hydrodissection liquid was injected. The rhesus monkey did not undergo ablation, was under general anesthesia instead of local anesthesia, and changed postures during the procedure. As a result, the distribution and movement of the liquid in the animal may have differed slightly from those in patients.

\section{Conclusion}

Continuous, large-volume hydrodissection could protect the vital structures around the thyroid throughout the RFA procedure, which might be particularly beneficial for large nodule ablation. Furthermore, animal experiments showed a potentially large space around the neck, and the mediastinum was able to store a large volume of hydrodissection liquid without causing airway compression.

\section{Statement of Ethics}

This study was approved by the Review Board of the Third Affiliated Hospital of Sun Yat-sen University and was registered at www.chictr.org.cn (ChiCTR-INR-16007884). The animal study was approved by the Institutional Animal Care and Use Committee (IACUC) of Sun Yat-sen University (No. 2018-175).

\section{Conflict of Interest Statement}

All authors have no conflicts of interest to declare.

\section{Funding Sources}

This study received funding by the General Program of the Natural Science Foundation of China (CN) (No. 81971632) and the 5010 Clinical Research Project of Sun Yat-sen University (No. 2016016).

\section{Author Contributions}

Yanping Ma contributed to literature research, experimental studies, statistical analysis, and manuscript drafting. Tao Wu contributed to clinical studies, experimental studies, and manuscript 
drafting. Zhicheng Yao contributed to literature research, experimental studies, and manuscript drafting. Bowen Zheng contributed to clinical studies and statistical analysis. Lei Tan contributed to clinical studies. Ge Tong contributed to statistical analysis. Yufan Lian contributed to statistical analysis. Jung Hwan Baek contributed to study design and manuscript editing. Jie Ren contributed to manuscript editing and study design and is the guarantor of integrity of the entire study.

\section{References}

1 Guth S, Theune U, Aberle J, Galach A, Bamberger CM. Very high prevalence of thyroid nodules detected by high frequency $(13 \mathrm{MHz})$ ultrasound examination. Eur J Clin Invest. 2009;39(8):699-706.

2 Moon WJ, Baek JH, Jung SL, Kim DW, Kim EK, Kim JY, et al. Ultrasonography and the ultrasound-based management of thyroid nodules: consensus statement and recommendations. Korean J Radiol. 2011;12(1):114.

3 Rosato L, Avenia N, Bernante P, De Palma M, Gulino G, Nasi P, et al. Complications of thyroid surgery: analysis of a multicentric study on 14,934 patients operated on in Italy over 5 years. World J surg. 2004;28(3):271-6.

4 Jin S, Sugitani I. Narrative review of management of thyroid surgery complications. Gland Surg. 2021;10(3):1135-46.

5 Kim YS, Rhim H, Tae K, Park DW, Kim ST. Radiofrequency ablation of benign cold thyroid nodules: initial clinical experience. Thyroid. 2006;16(4):361-7.

6 Jeong WK, Baek JH, Rhim H, Kim YS, Kwak MS, Jeong HJ, et al. Radiofrequency ablation of benign thyroid nodules: safety and imaging follow-up in 236 patients. Eur Radiol. 2008; 18(6):1244-50.

7 Lim HK, Lee JH, Ha EJ, Sung JY, Kim JK, Baek $\mathrm{JH}$. Radiofrequency ablation of benign nonfunctioning thyroid nodules: 4-year followup results for 111 patients. Eur Radiol. 2013; 23(4):1044-9.

8 Lin WC, Kan NN, Chen HL, Luo SD, Tung YC, Chen WC, et al. Efficacy and safety of single-session radiofrequency ablation for benign thyroid nodules of different sizes: a retrospective study. Int J Hyperthermia. 2020; 37(1):1082-9.

9 Wang JF, Wu T, Hu KP, Xu W, Zheng BW, Tong $\mathrm{G}$, et al. Complications following radiofrequency ablation of benign thyroid nodules: a systematic review. Chin Med J. 2017; 130(11):1361-70.

10 Sun PH, Hwan BJ, Whan PA, Rom CS, Jun CY, Hyun LJ. Thyroid radiofrequency ablation: updates on innovative devices and techniques. Korean J Radiol. 2017;18(4):615-23.

11 Na DG, Lee JH, Jung SL, Kim JH, Sung JY, Shin JH, et al. Radiofrequency ablation of benign thyroid nodules and recurrent thyroid cancers: consensus statement and recommendations. Korean J Radiol. 2012;13(2): $117-25$.

Large-Volume Hydrodissection in RFA of Thyroid Nodules

\section{Data Availability Statement}

The data that support the findings of this study are not publicly available due to their containing information that could compromise the privacy of research participants but are available from Ma (mayp3@mail2.sysu.edu.cn) upon reasonable request.
12 Kim JH, Baek JH, Lim HK, Ahn HS, Baek SM, Choi YJ, et al. 2017 Thyroid radiofrequency ablation guideline: Korean society of thyroid radiology. Korean J Radiol. 2018;19(4):632-55.

13 Xu D, Ge M, Yang A, Cheng R, Sun H, Wang $\mathrm{H}$, et al. Expert consensus workshop report: guidelines for thermal ablation of thyroid tumors (2019 edition). J Cancer Res Ther. 2020; 16(5):960-6.

14 Morelli F, Ierardi AM, Pompili G, Sacrini A, Biondetti P, Angileri SA, et al. Cooled tip radiofrequency ablation of benign thyroid nodules: preliminary experience with two different devices. Gland Surg. 2018 Apr;7(2):67-79.

15 Zhu Y, Zhang M, Jin Z, Tian X, Zhang Y, Xie $F$, et al. Solid benign thyroid nodules (> $10 \mathrm{~mL}$ ): a retrospective study on the efficacy and safety of sonographically guided ethanol ablation combined with radiofrequency ablation. Int J Hyperthermia. 2020;37(1):157-67.

16 Lu F, Xu H, Guo L, Sun L, Bo X, Zheng S, et al. Application of hydrodissection in percutaneous puncture of neck lesions with high risk under ultrasound guidance. Chin J Med Ultrasound. 2014;11(12):1006-9.

17 Dong P, Wu XL, Sui GQ, Luo Q, Du JR, Wang $\mathrm{H}$, et al. The efficacy and safety of microwave ablation versus lobectomy for the treatment of benign thyroid nodules greater than $4 \mathrm{~cm}$. Endocrine. 2021;71(1):113-21.

18 Lee MK, Baek JH, Chung SR, Choi YJ, Lee YM, Kim TY, et al. Effectiveness of injecting cold 5\% dextrose into patients with nerve damage symptoms during thyroid radiofrequency ablation. Endocrinol Metab. 2020; 35(2):407-15.

19 Cui R, Yu J, Han ZY, Liu FY, Yu XL, Liang P. Ultrasound-guided percutaneous microwave ablation for substernal goiter: initial experience. J Ultrasound Med. 2019;38(11):2883-91.

20 Moon W, Jung S, Lee J, Na D, Baek J, Lee Y, et al. Benign and malignant thyroid nodules: US differentiation: multicenter retrospective study. Radiology. 2008;247(3):762-70.

21 Ha EJ, Baek JH, Lee JH. Moving-shot versus fixed electrode techniques for radiofrequency ablation: comparison in an ex-vivo bovine liver tissue model. Korean J Radiol. 2014;15(6): 836-43.

22 Baek JH, Ha EJ, Choi YJ, Sung JY, Kim JK, Shong YK. Radiofrequency versus ethanol ablation for treating predominantly cystic thyroid nodules: a randomized clinical trial. Korean J Radiol. 2015;16(6):1332-40.
23 Sacks D, McClenny TE, Cardella JF, Lewis CA. Society of Interventional Radiology clinical practice guidelines. J Vasc Interv Radiol. 2003;14:S199-202.

24 Cardella JF, Kundu S, Miller DL, Millward SF, Sacks D. Society of Interventional Radiology clinical practice guidelines. J Vasc Interv Radiol. 2009;20:S189-91.

25 Baek JH, Lee JH, Sung JY, Bae JI, Kim KT, Sim $\mathrm{J}$, et al. Complications encountered in the treatment of benign thyroid nodules with USguided radiofrequency ablation: a multicenter study. Radiology. 2012;262(1):335-42.

$26 \mathrm{Hu} \mathrm{K}$, Lian Y, Wang J, Li W, Yao Z, Liu B, et al. Management of bleeding associated with radiofrequency ablation of benign thyroid nodules. J Int Med Res. 2020 Aug;48(8): 300060520937526.

27 Tang X, Cui D, Chi J, Wang Z, Wang T, Zhai $B$, et al. Evaluation of the safety and efficacy of radiofrequency ablation for treating benign thyroid nodules. J Cancer. 2017;8(5):754-60.

28 Nair A, Morsy MA, Jacob S. Dose translation between laboratory animals and human in preclinical and clinical phases of drug development. Drug Dev Res. 2018;79(8):373-82.

29 Cesareo R, Palermo A, Pasqualini V, Cianni R, Gaspa G, Manfrini S, et al. Radiofrequency ablation for the management of thyroid nodules: a critical appraisal of the literature. Clin Endocrinol. 2017;87(6):639-48.

30 Yao Z, Wu T, Zheng B, Tan L, Lian Y, Liu B, et al. A novel strategy for single-session ultrasound-guided radiofrequency ablation of large benign thyroid nodules: a Pilot Cohort Study. Front Endocrinol. 2020;11:560508.

31 Biasotto M, Pellis T, Cadenaro M, Bevilacqua L, Berlot G, Di Lenarda R. Odontogenic infections and descending necrotising mediastinitis: case report and review of the literature. Int Dent J. 2004;54(2):97-102.

32 Weaver E, Nguyen X, Brooks MA. Descending necrotising mediastinitis: two case reports and review of the literature. Eur Respir Rev. 2010;19(116):141-9.

33 Chen G, Wang S. Common surgical complications of thyroid surgery. Bejing, China: People's Medical Publishing House; 2005. p. 402-3.

34 Fan C, Zhou X, Su G, Zhou Y, Su J, Luo M, et al. Risk factors for neck hematoma requiring surgical re-intervention after thyroidectomy: a systematic review and meta-analysis. BMC Surg. 2019;19(1):98. 